\title{
A mapping of martian water sublimation during early northern summer using OMEGA/Mars Express
}

\author{
T. Encrenaz ${ }^{1}$, R. Melchiorri ${ }^{1}$, T. Fouchet ${ }^{1}$, P. Drossart ${ }^{1}$, E. Lellouch ${ }^{1}$, B. Gondet ${ }^{2}$, J.-P. Bibring ${ }^{2}$, Y. Langevin ${ }^{2}$, \\ D. Titov $^{3}$, N. Ignatiev ${ }^{4}$, and F. Forget ${ }^{5}$
}

\author{
1 LESIA, Observatoire de Paris, 92195 Meudon, France \\ e-mail: Therese.Encrenaz@obspm.fr \\ 2 Institut d'Astrophysique Spatiale, Orsay Campus, 91405 Orsay, France \\ 3 MPI, Max-Planck St. 2, 37191 Katlenburg-Lindau, Germany \\ ${ }^{4}$ IKI, Profnoyuznaya 87/32, Moscow 117997, Russia \\ 5 IPSL/LMD, place Jussieu, 75231 Paris cedex 05, France
}

Received 13 July 2005 / Accepted 9 August 2005

\section{ABSTRACT}

The OMEGA imaging spectrometer aboard Mars Express has been used to map the water vapor abundance over the martian surface, from the analysis of the $2.6 \mu \mathrm{m}$ band of $\mathrm{H}_{2} \mathrm{O}$. As a preliminary result of this study, we present water vapor maps in the northern hemisphere at the time of the northern polar cap sublimation ( $L \mathrm{~s}=94-112 \mathrm{deg}$ ). The maps show a mean $\mathrm{H}_{2} \mathrm{O}$ mixing ratio of about $2-3 \times 10^{-4}$ at a latitude of $40 \mathrm{~N}$, and in the range of $5 \times 10^{-4}-10^{-3}$ at $60 \mathrm{~N}-80 \mathrm{~N}$ latitudes. The corresponding mean $\mathrm{H}_{2} \mathrm{O}$ column densities are about $25 \mathrm{pr}-\mu \mathrm{m}$ at $40 \mathrm{~N}$ and between 40 and $60 \mathrm{pr}-\mu \mathrm{m}$ at $60 \mathrm{~N}-80 \mathrm{~N}$, with uncertainties of about 30 percent. Our results are in agreement with previous results by MAWD/Viking and TES/MGS for latitudes up to $60 \mathrm{~N}$, but seem to indicate lower values at high latitude. However they are still globally consistent in view of our error bars.

Key words. planets and satellites: Mars - infrared: solar system

\section{Introduction}

Water vapor on Mars is known to exhibit a complex seasonal cycle, associated to the periodic condensation and sublimation of $\mathrm{H}_{2} \mathrm{O}$ on each polar cap. Seasonal variations of water vapor on Mars have been monitored by the IRIS instrument aboard Mariner 9 (Conrath et al. 1973), then by the MAWD (Mars Atmospheric Water Detection) experiment (Farmer et al. 1977; Jakosky \& Farmer 1982; Fedorova et al. 2004) aboard the Viking orbiters. These observations have shown evidence for large spatial and temporal variations of the water column density, with maxima as high as $80 \mathrm{pr}-\mu \mathrm{m}$, at high northern latitudes, at the time of early northern summer $(L s=100-120 \mathrm{deg})$ and minima as low as $1-3 \mathrm{pr}-\mu \mathrm{m}$ in the opposite hemisphere at the same time (Jakosky \& Haberle 1992).

The MAWD experiment aboard Viking used a weak $\mathrm{H}_{2} \mathrm{O}$ absorption band near $1.38 \mu \mathrm{m}$, while the IRIS analysis was based upon rotational $\mathrm{H}_{2} \mathrm{O}$ transitions beyond $20 \mu \mathrm{m}$. Since the Viking observations, maps of the water vapor on Mars have been obtained by the Thermal Emission Spectrometer (TES) aboard the MGS (Mars Global Surveyor) spacecraft (Smith 2002, 2004). In the TES study, as in the case of the IRIS analysis from Mariner 9, the water content was retrieved from the study of thermal $\mathrm{H}_{2} \mathrm{O}$ rotational lines. This method requires the knowledge of the temperature profile, retrieved from the inversion of the $\mathrm{CO}_{2} v_{2}$ band at $15 \mu \mathrm{m}$. The OMEGA instrument aboard the Mars Express orbiter offers an alternative method for retrieving the water vapor abundance through the analysis of the $\left(v_{1}, v_{3}\right)$ bands of $\mathrm{H}_{2} \mathrm{O}$ at $2.6 \mu \mathrm{m}$. As these bands appear in the reflected sunlight component of the spectrum, this analysis, like the method used by MAWD, has the advantage of being, to first order, independent of the temperature profile. It also applies to the polar caps where thermal measurements are not possible. In this letter, we present a study of the water vapor abundance of Mars at the time of its maximum abundance in the seasonal cycle, when the $\mathrm{H}_{2} \mathrm{O}$ seasonal northern cap starts to sublimate during early northern summer ( $L s=94-112 \mathrm{deg})$.

\section{The OMEGA instrument aboard Mars Express}

The Mars Express spacecraft, launched by ESA on June 2, 2003, has been operating in a quasi-polar orbit around Mars since January 2004. Aboard Mars Express, the OMEGA imaging spectrometer operates from the visible $(0.3 \mu \mathrm{m})$ to the thermal infrared $(5.2 \mu \mathrm{m})$ with a spectral sampling of $7 \mathrm{~nm}$ below $1 \mu \mathrm{m}, 14 \mathrm{~nm}$ in the $1.0-2.5 \mu \mathrm{m}$ range, and $20 \mathrm{~nm}$ above $2.5 \mu \mathrm{m}$. Its instantaneous field of view (IFOV) of $1.2 \mathrm{mrad}$ 
corresponds to about $300 \mathrm{~m}$ at the martian surface near periapsis. The crosstrack FOV (perpendicular to the spacecraft motion) varies from 16 to 128 IFOV depending on the operating mode of the observing sequence.

Figure 1 shows the ratio of two averaged OMEGA spectra between 1.0 and $2.7 \mu \mathrm{m}$, recorded at the foot and at the summit of Olympus Mons respectively (Orbit 37-3). This ratio exhibits strong absorption features, mostly due to $\mathrm{CO}_{2}$. Indeed, the $\mathrm{CO}_{2}$ absorption bands are stronger on the Olympus foot spectrum because the $\mathrm{CO}_{2}$ column density above the surface is larger. In order to eliminate the uncertainty associated with the OMEGA instrumental transfer function, we have divided each individual spectrum by the averaged spectrum of the Olympus summit, taken as a reference. This method can be applied because of the great stability of the instrumental parameters over the whole observing period.

\section{Modelling of the atmospheric spectrum}

The absorption due to the martian atmospheric gases was calculated over the $1.0-2.7 \mu \mathrm{m}$ range, using a line-by-line radiative transfer code including the spectral signatures of $\mathrm{CO}_{2}, \mathrm{H}_{2} \mathrm{O}$ and CO. Spectroscopic parameters were taken from the GEISA data bank (Jacquinet-Husson 1999). Line-broadening parameters for $\mathrm{CO}_{2}-\mathrm{CO}_{2}$ collisions and $\mathrm{H}_{2} \mathrm{O}-\mathrm{CO}_{2}$ collisions were taken from (Pollack et al. 1993) and references therein. The atmospheric parameters were taken from the Global Climate Model (GCM) developed at LMD-Oxford (Forget et al. 1999). For the calculations corresponding to the Olympus Mons spectra (Orbit 37-3; Ls = $337 \mathrm{deg}$ ), the surface temperature was in the range $275-280 \mathrm{~K}$; the assumed atmospheric temperature was $250 \mathrm{~K}$ at $P=7.5 \mathrm{mbars}, 200 \mathrm{~K}$ at $1.6 \mathrm{mbars}$, and about $150 \mathrm{~K}$ at pressures lower than $0.1 \mathrm{mbar}$ (at altitudes higher than $45 \mathrm{~km}$ ). Calculations were performed with a frequency step of $0.01 \mathrm{~cm}^{-1}$, then convolved with the OMEGA instrumental function.

In Fig. 1, the ratio of the Olympus foot spectrum by the Olympus summit spectrum is compared to a set of synthetic models. The $\mathrm{CO}_{2}$ signatures are strong at $2.75\left(v_{1}+v_{3}\right)$ and $2.0 \mu \mathrm{m}\left(2 v_{1}+v_{3}\right)$, while weaker bands appear at $1.44 \mu \mathrm{m}\left(3 v_{3}\right)$ and $1.6 \mu \mathrm{m}\left(3 v_{1}+v_{3}\right) . \mathrm{H}_{2} \mathrm{O}$ shows a clear signature at $2.6 \mu \mathrm{m}$ $\left(v_{1}, v_{3}\right.$, in the wing of the strong $\mathrm{CO}_{2}$ band at $\left.2.7 \mu \mathrm{m}\right)$ while two weaker water features appear at $1.38 \mu \mathrm{m}\left(v_{1}+v_{3}\right)$ and $1.9 \mu \mathrm{m}$ (hydratation band). The $2.6 \mu \mathrm{m}$ band is most favorable because it is a factor 3 to 5 times stronger than the other ones, and because the $2.6 \mu \mathrm{m}$ spectral range is expected to be free of mineralogic signatures.

\section{Analysis of the $2.6 \mu \mathrm{m} \mathrm{H}_{2} \mathrm{O}$ band}

In order to determine the atmospheric parameters associated to the reference spectrum, we have used the MOLA data to determine the altitude of the spectra locations, at the summit and at the foot of Olympus Mons respectively, and the GCM thermal profile associated to this region. Following the GCM database, we used a surface pressure of $1.1 \mathrm{mbar}$ at the Olympus summit and, from the best fit of the $\mathrm{CO}_{2}$ bands (Fig. 1), we inferred a surface pressure of $7.5 \mathrm{mbar}$ at the location of the

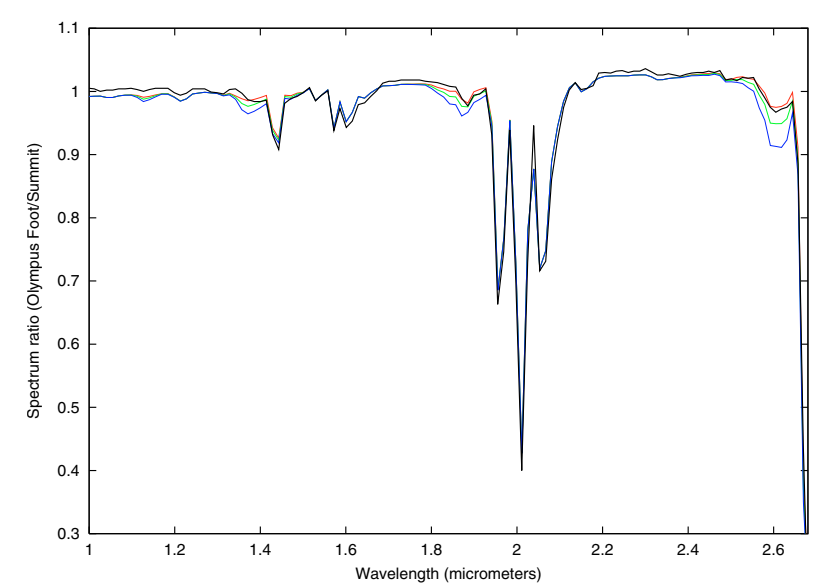

Fig. 1. Black curve: ratio of two averaged OMEGA raw spectra, recorded at the foot (lat $=30 \mathrm{~N}$, long $=227 \mathrm{E})$ and at the summit (lat $=$ $17 \mathrm{~N}$, long = 227E) of Olympus Mons respectively (Orbit 37-3). Each spectrum is the average of 352 individual spectra, corresponding to 11 pixels along the latitude (spacecraft motion) and 32 pixels along the longitude. Color curves: synthetic ratio of spectra calculated with averaged $P$ s values of $1.1 \mathrm{mbar}$ at the summit and $7.5 \mathrm{mbar}$ at the foot. A constant mixing ratio is assumed for $Q\left(\mathrm{H}_{2} \mathrm{O}\right)$. Red: $Q\left(\mathrm{H}_{2} \mathrm{O}=\right.$ 150 ppm; green: $Q\left(\mathrm{H}_{2} \mathrm{O}\right)=300$ ppm; blue: $Q\left(\mathrm{H}_{2} \mathrm{O}\right)=600 \mathrm{ppm}$. The best fit is achieved for $Q\left(\mathrm{H}_{2} \mathrm{O}\right)=150 \mathrm{ppm}$.

foot spectrum; this value is also in good agreement with the GCM predictions. We then assumed a constant mixing ratio of $\mathrm{H}_{2} \mathrm{O}$ at the two locations, and we inferred an $\mathrm{H}_{2} \mathrm{O}$ mixing ratio of $150 \mathrm{ppm}$ from the best fit of the $2.6 \mu \mathrm{m} \mathrm{H}_{2} \mathrm{O}$ band. This allows us to calculate a synthetic spectrum associated to our reference spectrum. The corresponding $\mathrm{H}_{2} \mathrm{O}$ column density is $1.6 \mathrm{pr}-\mu \mathrm{m}$.

It has to be mentioned that there is some uncertainty associated with the assumption of a constant mixing ratio over the Olympus region. If the $\mathrm{H}_{2} \mathrm{O}$ mixing ratio at the summit were twice its value at the foot, the corresponding column density at the summit would be $3.2 \mathrm{pr}-\mu \mathrm{m}$, while it could be as low as zero if $\mathrm{H}_{2} \mathrm{O}$ were significantly depleted at the summit. However, as the expected abundances of $\mathrm{H}_{2} \mathrm{O}$ are above $50 \mathrm{pr}-\mu \mathrm{m}$ at high northern latitude at the time of the northern polar cap sublimation, this uncertainty should be less than a few percent.

Synthetic calculations show that the depths of the $\mathrm{H}_{2} \mathrm{O}$ bands depend not only upon the $\mathrm{H}_{2} \mathrm{O}$ column density but also upon the pressure. In order to infer the water vapor content from the OMEGA data, one must also determine the surface pressure corresponding to each individual spectrum. A possible method could be to study the variations of the depth of the weak $\mathrm{CO}_{2}$ band at $1.44 \mu \mathrm{m}$ as a function of the surface pressure. However, this method has two inconvenients. First, for large water contents, the $1.44 \mu \mathrm{m} \mathrm{CO}_{2}$ band is contaminated by the $1.38 \mu \mathrm{m} \mathrm{H}_{2} \mathrm{O}$ band (Fig. 1). Second, the $\mathrm{CO}_{2}$ gaseous bands cannot be used if water ice is present (Fig. 2) due to the presence of strong and broad absorption bands centered at $1.5 \mu \mathrm{m}$ and $2.0 \mu \mathrm{m}$. Water ice extends at northern latitudes higher than $80 \mathrm{~N}$ (Langevin et al. 2005). For these reasons, we have used the surface pressure predicted by the GCM on the basis of the MOLA data. 


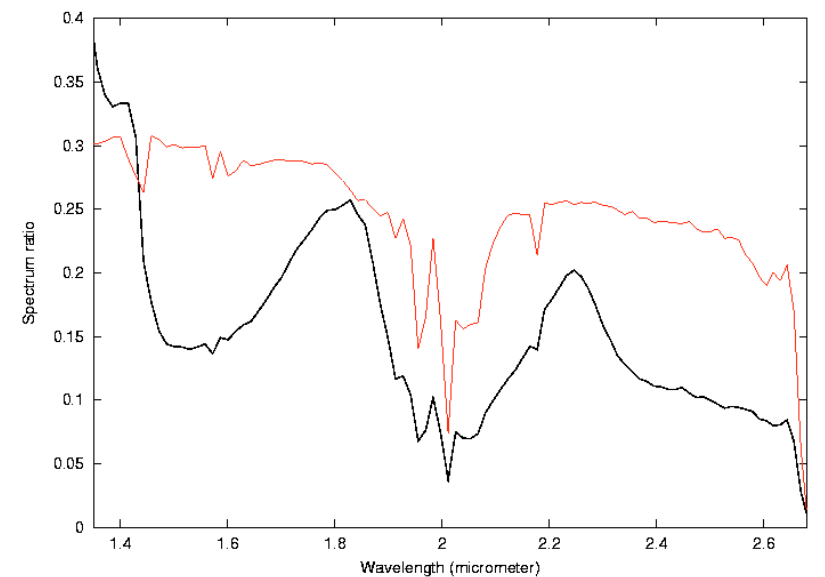

Fig. 2. Black line: a spectrum of Mars (divided by the reference spectrum of Olympus summit) recorded on Orbit 902-1 (lat. above 80N) showing two strong and broad bands at $1.5 \mu \mathrm{m}$ and $2 \mu \mathrm{m}$, characteristic of water ice. Red line: another spectrum of the same orbit (divided by the same reference), taken at a lower northern latitude (below $80 \mathrm{~N}$ ), is also shown for comparison; the water ice bands are absent.

In order to infer the water content from the depth of the $2.6 \mu \mathrm{m} \mathrm{H}_{2} \mathrm{O}$ band, we have built a grid of curves of growth using as entry parameters the $\mathrm{H}_{2} \mathrm{O}$ mixing ratio $Q$ at the surface and the surface pressure $P \mathrm{~s}$. The temperature profile was inferred from the GCM corresponding to the conditions of Orbit 37-3, which was used for validating our calculations.

Our method has then been applied to the conditions of early northern summer by using the relevant atmospheric temperature profile. This profile was selected from the GCM as a mean value of $T(z)$ at high northern latitudes $(65 \mathrm{~N})$, averaged over longitude, for $L s=90-120 \mathrm{deg}$. This thermal profile is significantly colder than the first one we used (corresponding to the conditions of Orbit $37, L s=337 \mathrm{deg}$ ), with a maximum difference of about $10 \mathrm{~K}$ (for a given pressure) in the lower atmosphere (below $10 \mathrm{~km})$. The new surface temperature $T \mathrm{~s}(240 \mathrm{~K})$ is about $40 \mathrm{~K}$ lower than its value on Olympus Mons at the time of the OMEGA observations. Nevertheless, calculations show that the temperature has a very minor effect on the $\mathrm{H}_{2} \mathrm{O}$ depth at $2.6 \mu \mathrm{m}$, as the calculated depth varies at maximum by $2-3$ percent over the whole range of atmospheric parameters. As a result, the difference in the $\mathrm{H}_{2} \mathrm{O}$ column density is $3 \mathrm{pr}-\mu \mathrm{m}$ for an $\mathrm{H}_{2} \mathrm{O}$ content of $80 \mathrm{pr}-\mu \mathrm{m}$. As mentioned above, we used for eachs spectrum the surface pressure interpolated from the GCM grid.

\section{Results}

Figures 3-5 show 3 maps of the $\mathrm{H}_{2} \mathrm{O}$ mixing ratio in the northern region for different values of $L s$. Mean values are in the range of $2-3 \times 10^{-4}$ at a latitude of $40 \mathrm{~N}$, and $5-10 \times 10^{-4}$ at $60 \mathrm{~N}-80 \mathrm{~N}$.

The measurement of the water vapor mixing ratio at the surface allows to infer directly the sublimation rate of $\mathrm{H}_{2} \mathrm{O}$ (if the surface temperature is known), independently of the altitude of the observed location. It is also interesting to convert our results in terms of water vapor column density (which is actually the

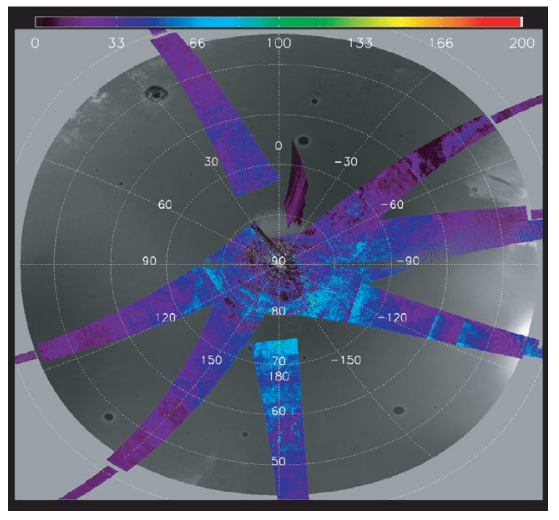

Fig. 3. The $\mathrm{H}_{2} \mathrm{O}$ mixing ratio at high northern latitudes for $L \mathrm{~s}=94 \mathrm{deg}$. The projection is centered on the north pole. Northern latitudes are indicated at the center of the figure, and eastern longitudes are shown along the $70 \mathrm{~N}$ parallel. The scale of the $\mathrm{H}_{2} \mathrm{O}$ mixing ratio ranges from 0 to $2 \times 10^{-3}$. A mixing ratio of $10^{-3}$ corresponds to a column density of about $65 \mathrm{pr} \mu \mathrm{m}$. This figure includes data from orbits $886-888,891$, 892, 894, 895, 898, 902, 905, 907, 909.

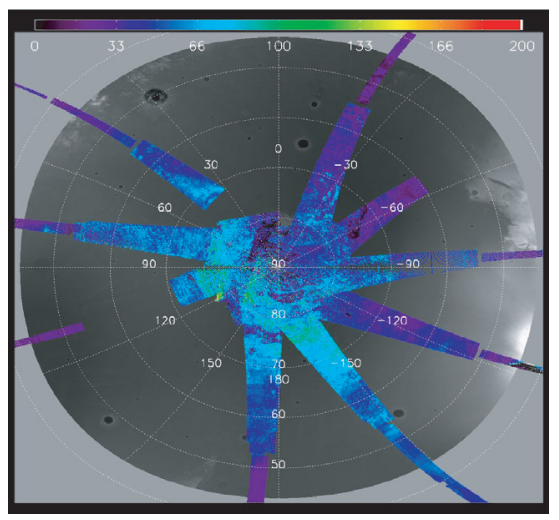

Fig. 4. Same as Fig. 3, with $L \mathrm{~s}=102.5 \mathrm{deg}$. This figure includes data from orbits 946, 954, 955, 961, 962, 964-967, 970-972 .

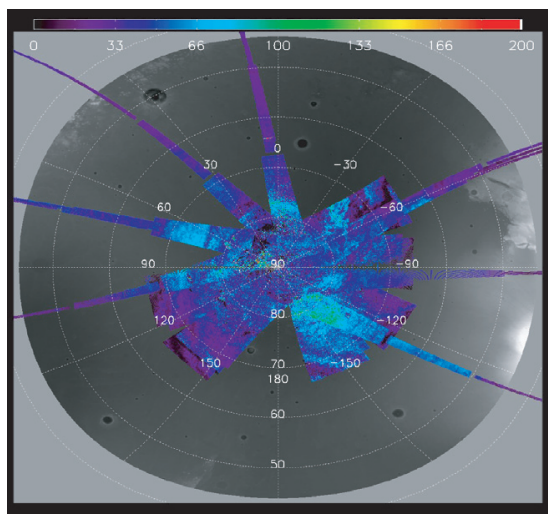

Fig. 5. Same as Fig. 3, for $L s=112$ deg. This figure includes data from orbits 1026, 1029, 1030, 1032, 1034, 1037, 1040, 1041, 1043, 1047, $1048,1050$.

observed parameter), for comparison with other measurements using this unit. For this we need to know the surface pressure of each spectrum. As shown by the GCM data, the surface pressure at $70 \mathrm{~N}-80 \mathrm{~N}$ typically ranges between 7.5 and 9.5 mbars. Figure 6 shows the relationship between the $\mathrm{H}_{2} \mathrm{O}$ surface 


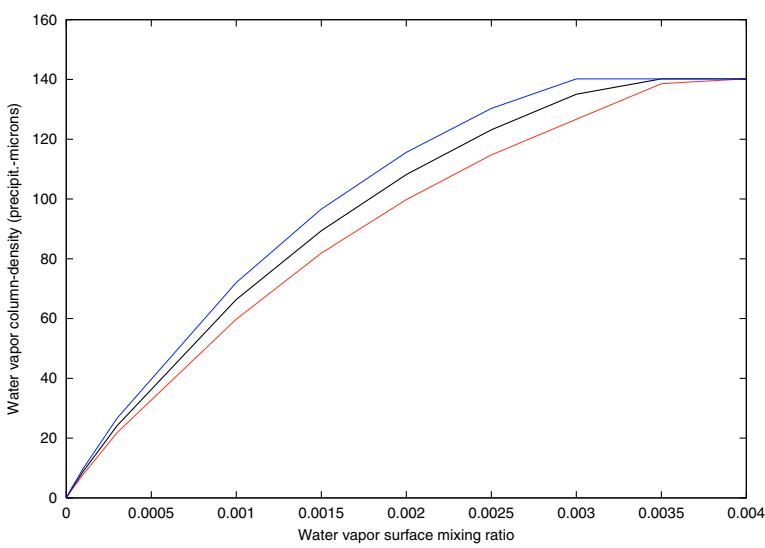

Fig. 6. The water vapor column density as a function of its surface mixing ratio. Surface pressures: 7.5 mbars (red), 8.5 mbars (black), 9.5 mbars (blue).

mixing ratio and the $\mathrm{H}_{2} \mathrm{O}$ column density in pr- $\mu \mathrm{m}$, assuming $T \mathrm{~s}=240 \mathrm{~K}, T(z=0)=220 \mathrm{~K}$, and 3 values of $P \mathrm{~s}(7.5,8.5$ and 9.5 mbars). Saturation becomes to play a role for column densities higher than about $20 \mathrm{pr}-\mu \mathrm{m}$. As the water content increases, saturation occurs at lower and lower altitudes, to reach the zero altitude level for surface mixing ratios higher than $3.5 \times 10^{-3}$. The corresponding column density would be $140 \mathrm{pr}-\mu \mathrm{m}$. For a surface pressure of $7.5 \mathrm{mbars}$, a water mixing ratio of $1.5 \times 10^{-3}$ (corresponding to $80 \mathrm{pr}-\mu \mathrm{m}$ ) corresponds to a saturation altitude of about $6 \mathrm{~km}$.

\section{Discussion}

Our results on the water vapor abundance can be compared to those of Viking Jakosky \& Haberle (1992) and TES (Smith 2002, 2004). From Figs. 3-5, we infer, at $40 \mathrm{~N}$ latitude range, a mean $\mathrm{H}_{2} \mathrm{O}$ column density of 20-25 pr- $\mu \mathrm{m}$, approximately constant over the 94-112 deg $L$ s range. The corresponding values are also between 20 and $25 \mathrm{pr}-\mu \mathrm{m}$ for both TES Smith (2004) and Viking. At $60 \mathrm{~N}$, we derive an $\mathrm{H}_{2} \mathrm{O}$ content between about $25 \mathrm{pr}-\mu \mathrm{m}(L \mathrm{~s}=94 \mathrm{deg})$ and $45 \mathrm{pr}-\mu \mathrm{m}(L \mathrm{~s}=112 \mathrm{deg})$, to be compared with Viking and TES (Smith 2004) values increasing from 30 to $50 \mathrm{pr}-\mu \mathrm{m}$. At $80 \mathrm{~N}$, our results appear to be lower than TES and Viking with a mean maximum column density of about $55 \mathrm{pr}-\mu \mathrm{m}$, while maximum values of 75 and $80 \mathrm{pr}-\mu \mathrm{m}$ were reported by Smith (2002) and Jakosky \& Haberle (1992). The GCM measurements are in general agreement with the TES results.
The uncertainty on our results has several sources (signal/noise ratio, temperature profile, modelling, surface pressure, water content over Olympus Mons, incomplete longitude coverage). The uncertainty on the $\mathrm{H}_{2} \mathrm{O}$ line depth, in an individual spectrum, ranges between 10 and 25 percent, depending upon the continuum level (see Fig. 2), and is probably our major source of error. We take a conservative estimate of about 30 percent our global uncertainty. In view of this error bar, there is no strong evidence for interannual variations of the maximum water vapor column density, although our results for $L \mathrm{~s}=$ 112 deg could indicate a lower $\mathrm{H}_{2} \mathrm{O}$ content as compared to the previous years. A more refined analysis of the OMEGA data will be needed to confirm this tendency.

In summary, the retrieval of the water vapor column density from the $2.6 \mu \mathrm{m}$ reflected band of $\mathrm{H}_{2} \mathrm{O}$ appears to be a powerful and promising method for measuring the water vapor content of Mars. This preliminary study will be completed in the future using a larger dataset, and will be later extended to monitor the water vapor abundance over the whole seasonal cycle at all latitude ranges.

\section{References}

Conrath, B. J., Curran, R., Hanel, R., et al. 1973, J. Geophys. Res., 78, 4267

Farmer, C. B., Davis, D. W., Holland, A. L., et al. 1977, J. Geophys. Res., 82, 4225

Fedorova, A. A., Rodin, A. V., \& Baklanova, I. V. 2004, Icarus, 171, 54

Forget, F., Hourdin, F., Fournier, R., et al. 1999, J. Geophys. Res., 104, 24155

Jacquinet-Husson, N., et al. 1999, J. Quant. Spectr. Rad. Transfer, 62, 205

Jakosky, B. M., \& Farmer, C. B. 1982, J. Geophys. Res., 87, 2999

Jakosky, B. M., \& Haberle, R. M. 1992, in Mars, ed. H. H. Kieffer et al. (University of Arizona Press)

Langevin, Y., Poulet, F., Bibring, J.-P., et al. 2005, Science, 307, 1581

Pollack, J. B., Dalton, J. B., Grinspoon, D., et al. 1993, Icarus, 103, 1

Smith, M. D. 2002, J. Geophys. Res., 107, E11, 5115, doi:10.1029/2001/JE001522

Smith, M. D. 2004, Icarus, 167, 148 